\title{
“A Corrida de Números": uma proposta de jogo no Ensino Fundamental
}

Rafael Rix Geronimo

Henry Guimarães Teixeira

\section{Resumo}

Apresentamos aqui um relato da elaboração e proposta do jogo Corrida dos Números para o primeiro ano do ensino fundamental de uma escola pública, na periferia da cidade de São Paulo. Essa proposta tem como objetivo verificar a possibilidade de um jogo de tabuleiro ser uma estratégia relevante para introdução e treino da relação entre o algarismo e a quantidade, que é importante na construção da noção de número. O público alvo, de nosso jogo, foram cinco alunos do primeiro ano do ensino fundamental, essas crianças tinham, em média, seis anos de idade. Essa pesquisa utilizou como metodologia o estudo de caso e foi composta de cinco sessões, de quarenta minutos cada. Como resultados, observamos o engajamento da turma com a atividade, também foi possível observar que alunos construíram a relação entre número e quantidade com a ajuda do jogo. É possível que esse jogo sirva de diagnóstico sobre o conhecimento dos estudantes e é digna de nota a vontade dos professores dos primeiros anos, nessa escola, de aplicar atividades diferenciadas para o ensino. Também refletimos sobre a importância, para a sociedade, da criação de jogos, desde comerciais até pedagógicos, com temáticas relevantes que problematizem desde questões relacionadas a problemas da sociedade até práticas de ensino.

Palavras chave: jogo de tabuleiro, ensino fundamental, quantidade e algarismo. 


\title{
"A Corrida de Números": a game proposal in Elementary School
}

\author{
Rafael Rix Geronimo \\ Henry Guimarães Teixeira
}

\begin{abstract}
We present here an account of the elaboration and proposal of the Race of Numbers game for the first year of elementary school in a public school on the outskirts of the city of São Paulo. This proposal aims to verify the possibility of a board game being a relevant strategy for introducing and training the relationship between number and quantity, which is important in the construction of the notion of number. The target audience of our game were five first grade students, these children were on average six years old. This research used as methodology the case study and was composed of five sessions, of forty minutes each. As results, we observed the engagement of the class with the activity, it was also possible to observe that students built the relationship between number and quantity with the help of the game. It is possible that this game serves as a diagnosis of the students' knowledge and it is worthy of note the willingness of the teachers of the early years, in this school, to apply differentiated activities for teaching. We also reflected on the importance to society of creating games, from commercial to pedagogical, with relevant themes that problematize from issues related to problems in society to teaching practices.
\end{abstract}

Keywords: board game, elementary school, quantity and digit. 


\section{Introdução}

A obrigatoriedade do ensino a partir dos quatro anos, introduzida na Lei de Diretrizes e Bases da Educação, em 2013, trouxe a escola a problemática de como acolher as crianças de 4, 5 e 6 anos de idade. Mais do que isso, existe a questão de como começar o ensino sobre os números um ano antes do que era feito, até então. Essa questão é pertinente, pois, muitas vezes, nem mesmo o mobiliário e o espaço físico é adequado a essas crianças, que dirá as atividades de ensino. Assim, propostas de atividades diferenciadas, como jogos, adquirem ainda mais importância nesse momento da escolarização.

Nossa proposta é a introdução do jogo “A Corrida dos Números” para tratar da relação entre algarismo e quantidade para alunos de seis anos de idade, de uma escola pública da periferia da cidade de São Paulo. Esse é um jogo de percurso em que, para avançar no tabuleiro, o aluno deve estabelecer a relação de uma carta de quantidade, sorteada aleatoriamente, e as cartas de algarismos do tabuleiro.

Durante o jogo, aqueles que não conseguem estabelecer as relações pedidas, em cada jogada, deixam de avançar no percurso proposto, no tabuleiro. Vence o jogo o primeiro a percorrer todo o tabuleiro.

Durante a aplicação foi possível notar que alguns alunos contavam a quantidade para jogar, essa atitude denota que eles já conheciam a relação entre o número e a quantidade. É provável que o ato de contar estivesse atrelado à vontade de acertar seu lance e ganhar o jogo. Também é possível que o estudante não tenha entendido completamente como estabelecer essa relação entre o número e a quantidade, pois em jogadas em que não contaram, esses estudantes erraram a quantidade e, por conseguinte, a jogada.

Outra variável percebida, na aplicação do jogo, ocorreu quando os jogadores erraram jogadas em que era pedido que relacionassem a quantidade com os números sete, oito e nove. Esses erros denotam que é mais difícil estabelecer a relação quando as quantidades são maiores.

Outro fato relevante, nessa pesquisa, foi de que o professor considerou o jogo como uma boa maneira de diagnosticar quais alunos estavam aptos a estabelecer relações entre quantidades e números. Um fato interessante, que constatamos, foi à receptividade da equipe docente a nossa proposta.

Esse fato nos leva a crer que os professores estão procurando novas maneiras de ensinar e que, na realidade, o que falta são novas propostas de ensino; novas propostas que incluam vivências lúdicas, para a sala de aula. Essa reflexão nos leva a um argumento defendido por Matar (2010) de que os jogos comerciais podem ajudar a ensinar.

Reconhecemos a importância de que os designers de jogos se preocupem com temáticas relevantes como, por exemplo, a problematização de como seria o mundo quando 
acabarem os combustíveis fósseis, como no jogo World Without Oil ${ }^{1}$, ou ainda a simulação da colonização e exploração do planeta Marte, como no jogo Terraforming Mars². Esses e outros problemas são importantes para a sociedade e são questionados em ambientes de jogo.

Consideramos que jogos podem ajudar a pensar questões relevantes, mas, em nossa visão, os jogos comerciais não são suficientes para ensinar conteúdos do currículo. Para dar conta dessa tarefa, precisamos de jogos criados com intenções pedagógicas.

Sem essa intencionalidade, é impossível dar conta de propostas de ensino. Assim, concordamos com autores como Matar (2010) e McGonigal (2012), de que os jogos são um importante meio de ensino de conceitos e de atitudes e que eles terão um papel cada vez maior na sociedade do século XXI. Concordamos que as novas gerações já estão nascendo cercadas pelas modernas tecnologias da informação e comunicação e que elementos como jogos são cada vez mais naturais para essas pessoas.

Assim, nossa proposta é a de que mais jogos sejam propostos por especialistas em educação e que, com o tempo, os especialistas tenham condição de lançar jogos educativos com a qualidade dos jogos comerciais, como propôs Geronimo (2017). Consideramos esse um movimento que precisa ser considerado como meta para o futuro, visto que existe uma demanda por esse tipo de material tanto por professores, como pela própria sociedade.

\section{O Uso de Jogos como Estratégia Pedagógica}

Muito tem se discutido sobre como ensinar no século XXI. Desde a ideia de que o currículo tradicional da escola precisa ser abolido em troca de um novo currículo interdisciplinar, focado na narrativa (MEIRA E PINHEIRO, 2017). Até propostas de aprendizagem tangencial, que seria feita de maneira indireta, a partir do conceito de que a criança aprende ao ser exposta a informação (MATTAR, 2010).

Frente a essas novas propostas, é imperativo que nós, professores, pensemos maneiras de ensinar focadas na superação das estratégias tradicionais de ensino. Caso contrário, corremos o risco de que a escola deixar de existir.

Argumentações, como as expostas por Meira e Pinheiro (2017) e Mattar (2010), tem se tornado cada vez mais comuns, na atualidade. Cabe a reflexão do motivo de diversos pesquisadores pregarem o fim da escola tradicional. Em nossa visão, isso se deve a não termos

\footnotetext{
${ }^{1} \mathrm{http}: / /$ writerguy.com/wwo/metahome.htm, é um jogo de realidade alternativo criado para chamar a atenção, iniciar o diálogo, planejar e projetar soluções para uma possível escassez global de petróleo no futuro, após o pico do petróleo: https://en.wikipedia.org/wiki/World_Without_Oil

2 é um processo hipotético de engenharia planetária pelo qual o clima, atmosfera, superfície e outras propriedades naturais conhecidas do planeta Marte seriam deliberadamente alteradas com o objetivo de tornar o ambiente de grandes áreas de Marte mais favoráveis aos assentamentos humanos, e assim tornando muito mais segura e sustentável a colonização humana no planeta: https://pt.wikipedia.org/wiki/Terraforma\%C3\%A7\%C3\%A3o_de_Marte ISSN 2526-2882 
superado as estratégias tradicionais de ensino, mesmo que já se tenha chegado a certo consenso sobre o fracasso dessa abordagem (BRASIL, 1998).

Portanto, cabe ao debate especializado da área propor novas estratégias de ensino. Mais que uma questão de ensino, será uma questão de sobrevivência do currículo e da profissão de professor a proposição de novas formas de ensinar.

Assim, elaboramos e propomos, nesse artigo, um jogo para ensinar. Escolhemos tal abordagem por considerar o jogo uma atividade natural para as crianças desde a mais tenra de idade. Consideramos que os jogos são atividades naturais e são demandados por crianças, adolescentes e adultos. Nesse sentido, Huizinga (2008, p.03) comenta que o jogo é atividade comum a todos os seres e transcende a questão de idade e posição na sociedade.

Consideramos que essa proposta pode ser uma alternativa para tratar e dar significado a um tema do currículo de uma maneira lúdica (a saber, a construção da relação entre o algarismo e a quantidade) e que pode ajudar os estudantes a atribuir significado a diferentes conteúdos.

\section{Proposta de Atividade}

Nossa proposta era criar um jogo educativo para superar um problema de sala de aula do primeiro ano do ensino fundamental. Elegemos a relação entre o algarismo e a quantidade como conteúdo a ser trabalhado. Esse problema, de determinar qual quantidade corresponde a cada algarismo, é comum e relevante aos alunos desse nível de ensino. Consideramos tal relevância por estar previsto em BRASIL (2016) esse trabalho. Assim, estamos elegendo um tema do currículo em nossa proposta de atividade.

Elegido o conteúdo, buscamos criar um jogo para ajudar na introdução e treinamento desse conceito. Escolhemos um jogo de percurso e um tabuleiro com seis casas para serem percorridas. Essa opção, de seis casas, foi uma variável escolhida devido à experiência do professor da turma. O regente salientou que crianças, dessa faixa etária, trabalham melhor com atividades com duração entre 15 e 20 minutos.

Para ajudar na ludicidade da atividade, nosso tabuleiro é composto de duas margens de um rio, com seis pedras. Cada pedra representa parte do percurso que os jogadores terão de seguir, para vencer a partida, conforme nos mostra a Figura 1 a seguir. 
Figura 1: tabuleiro do jogo

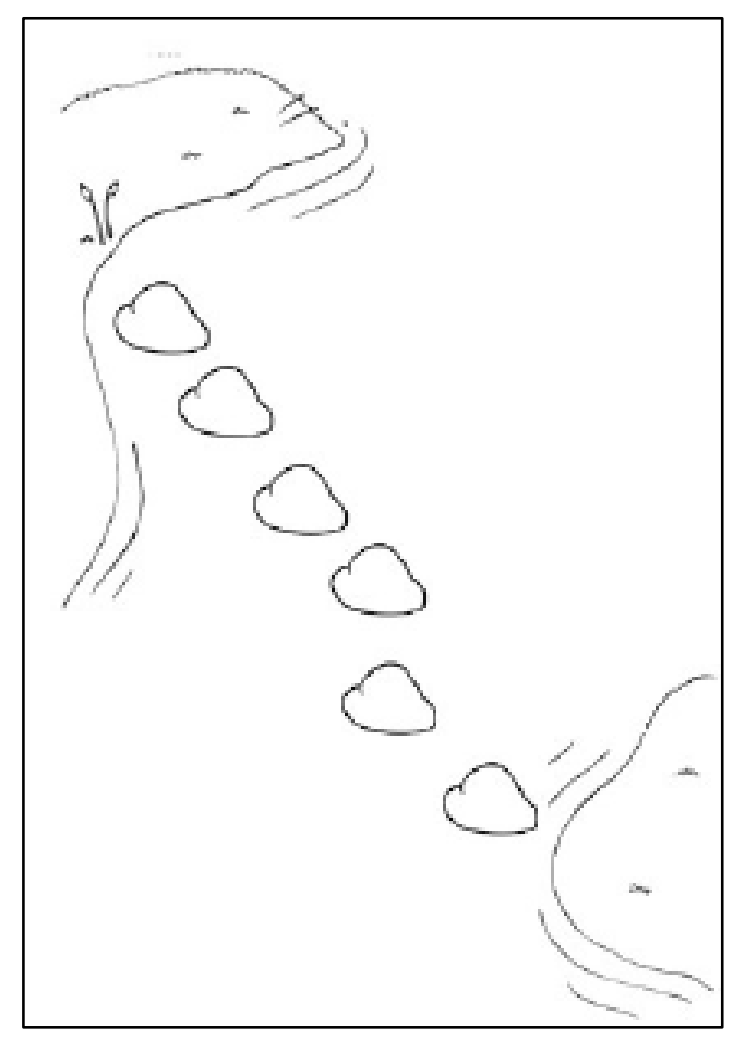

Fonte: Autores

Decidido o percurso, escolhemos a maneira de percorrê-lo. Pensamos em lançamento de dados, mas a aleatoriedade desse tipo de mecânica acabou sendo encarada como um obstáculo à concepção do jogo. Optamos por criar uma mecânica baseada em cartas para evitar o aleatório e favorecer a habilidade dos jogadores.

Escolhemos ter 10 cartas de algarismo (algarismos de o a 9) e 30 cartas de quantidades (também de o a 9), conforme ilustra a Figura 2.

Figura 2: cartas do jogo

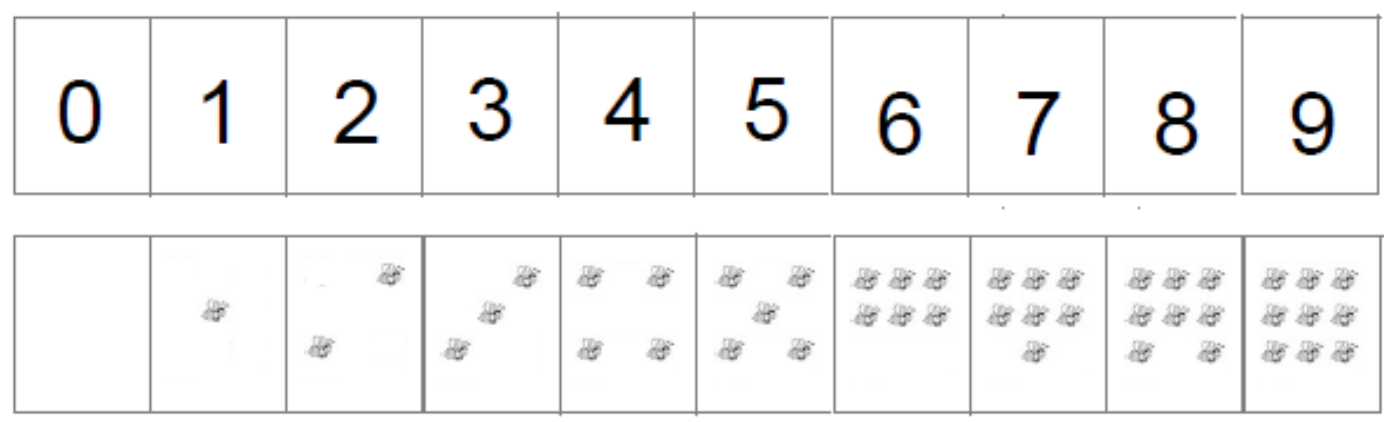

Fonte: Autores

Ademais, criamos as seguintes estratégias para o jogo:

1. A ideia era de que as cartas de algarismos ficariam dispostas de face para cima, ao lado do tabuleiro, e que seria feito um monte com as 30 cartas de quantidades. Esse monte de cartas, com quantidades, seria embaralhado e disposto com a face para baixo. 
Figura 3: tabuleiro pronto para o jogo

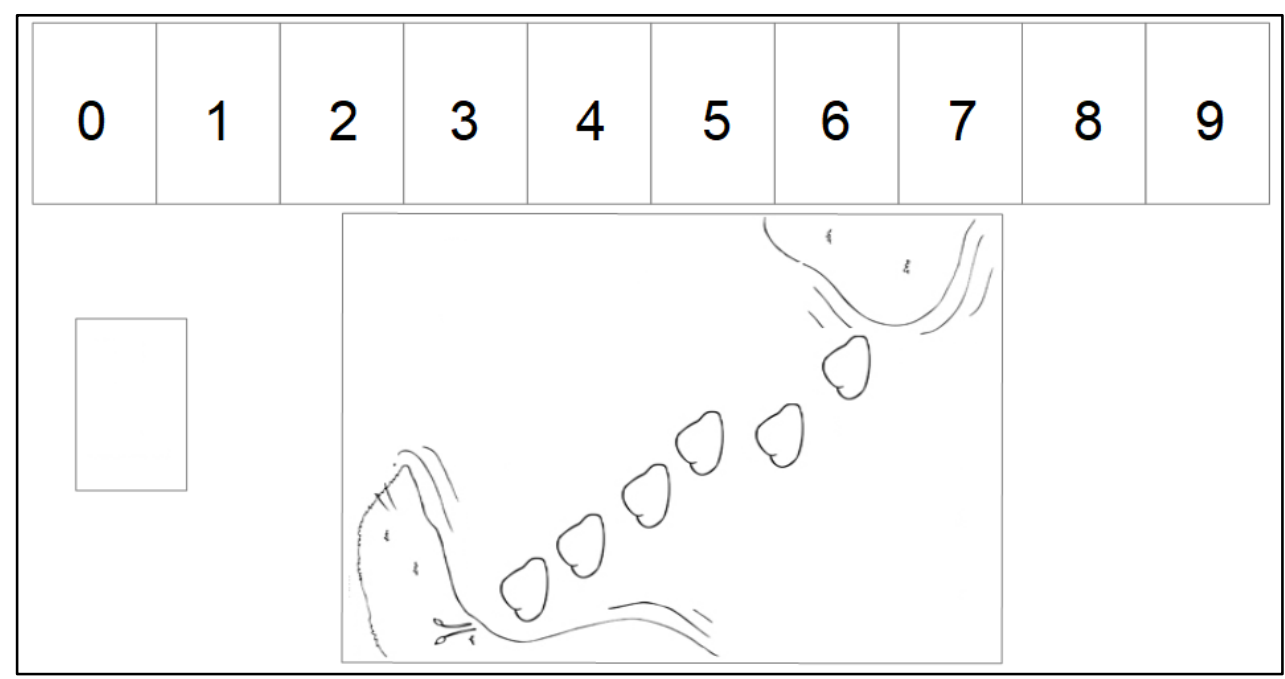

Fonte: Autores

2. A ideia do jogo "Corrida dos Números" é de que possam jogar de duas a cinco crianças de cada vez. A criança que inicia o jogo é escolhida por sorteio e, a partir dela, o próximo jogador será sempre o que está à esquerda do que realizou a última jogada.

3. A jogada consiste em pegar uma das cartas, que está virada para baixo. Essa carta representa um conjunto de elementos que devem corresponder a uma das cartas de algarismos, viradas para cima no tabuleiro. O jogador deve fazer a correspondência entre a quantidade e o algarismo correspondente.

Figura 4: jogada correta

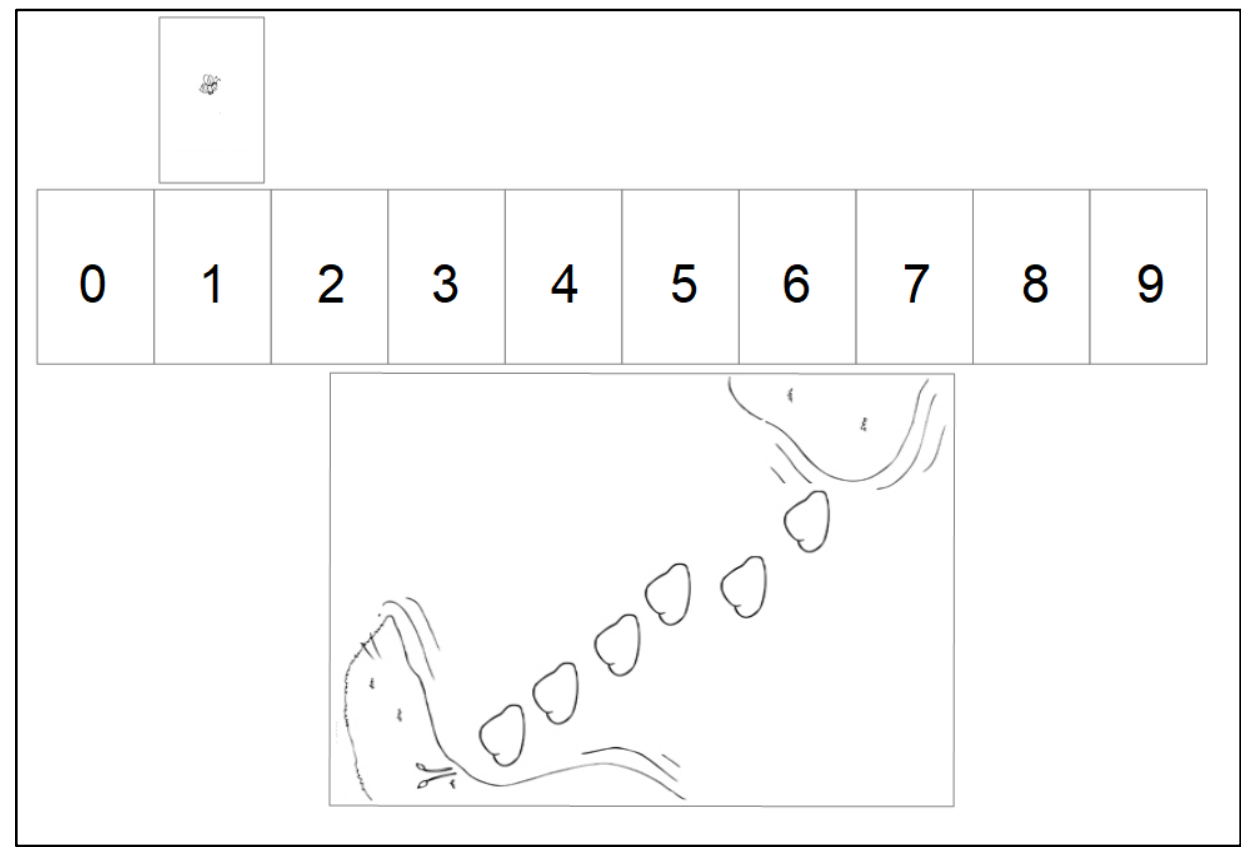

Fonte: Autores

ISSN 2526-2882

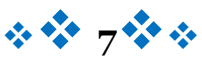


4. A cada jogada correta um boneco, que deve corresponder a cada um dos jogadores, percorre uma das casas do tabuleiro. Se a jogada não for correta, o boneco fica estacionado na mesma casa, até a próxima rodada. Ganha o jogo quem chegar ao fim do percurso. Se mais de um jogador chegar, no mesmo turno, no final do percurso, o jogo é considerado empatado.

\section{Algumas Justificativas dessa Proposta}

Os jogos são atividades naturais em nossa sociedade e, para BRASIL (2016), esse tipo de situação precisa ser valorizado e articulado com as situações de ensino. Concordamos com essa visão e, por isso, propomos esse jogo educativo matemático para auxiliar na construção da ideia da relação entre o algarismo e a quantidade.

A criação de relações e de argumentação, pelos estudantes, entre o número e a quantidade é uma habilidade importante. Nosso jogo pode ajudar nessa construção na medida em que, durante a partida, é necessário estabelecer essa relação para que a jogada seja bem sucedida.

Mais do que isso, quando propomos que a criança estabeleça a relação entre o número e a quantidade com um jogo, consideramos que estamos criando uma atividade que, além de educativa, é interessante para o estudante.

BRASIL (2016), propõe que as atividades de ensino precisam se organizar em torno de interesses dos estudantes. Por isso, consideramos que propostas diferenciadas são atividades de ensino permeadas de significados, pois poucas propostas são mais naturais às crianças do que jogos e brincadeiras.

Para além da questão da importância de brincar, é importante salientar que competências podem ser desenvolvidas pelos estudantes, ao interagir com esse ambiente, ou características conforme realça Mattar (2010). No “A Corrida dos Números” é possível que a criança desenvolva atitudes, tais como:

- $\quad$ Enfrentar problemas;

- Interagir com seus pares;

- $\quad$ Respeitar regras;

- $\quad$ Confiar em suas capacidades;

- $\quad$ Perseverar em busca de respostas.

Além dessas atitudes, é possível que durante o jogo os estudantes percebam a matemática como construção humana e que comecem a questionar os significados do que aprendem. Assim, jogos podem ajudar na construção de uma educação que forme pessoas com capacidade crítica, que formulem e testem hipóteses. 
É importante salientar que BRASIL (2016) pressupõe que a aprendizagem em matemática se relacione com a compreensão e apreensão de significados e considera os jogos como um importante recurso didático. Concordamos com esse pressuposto e, por isso, criamos esse jogo educativo matemático para ajudar na compreensão da relação entre número e quantidade, em um ambiente lúdico.

\section{Metodologia do estudo}

A metodologia escolhida para nossa pesquisa foi o estudo de caso, Severino (2007) comenta que esse tipo de pesquisa se concentra em um caso específico e particular desde que permita generalização para outros casos.

Assim, aplicamos cinco sessões do protótipo de nosso jogo com cinco alunos de uma turma de seis anos de idade de uma escola pública da periferia de São Paulo. Na primeira sessão de jogo, o aplicador da atividade contou uma história aos alunos, como introdução ao jogo. A história é como segue:

Em um dia ensolarado, um grupo de indígenas saiu para brincar. No meio da bagunça e das brincadeiras, eles encontraram uma colmeia de abelhas. O problema é que as abelhas também os encontraram! Agora todos devem correr o mais rápido possível. Ajude-os a fugir dessa grande confusão!

O percurso, mostrado no tabuleiro, servia de rota de fuga aos índios e essa foi a introdução ao jogo. Após essa introdução, o aplicador explicou as regras do jogo e deu exemplos. Depois pediu aos alunos que jogassem. Percebemos que as crianças, mesmo as mais indisciplinadas, se esforçaram durante as partidas.

A observação sobre esse comportamento faz com que concordemos com Ide (2009). A autora aponta que, para se obter melhores resultados nos jogos, as crianças tendem a se esforçar mais, pois querem jogar bem, e essa motivação se traduz em maior atividade para superação de problemas. Nas sessões de aplicação do jogo, cada partida durou, em média, 20 minutos.

\section{Considerações}

Durante a aplicação do jogo, alguns alunos contavam a quantidade de abelhas para jogar, essa atitude denota que eles já conheciam a relação entre o número e a quantidade. A questão da contagem das abelhas demonstra que, apesar de saber que existe uma relação entre o número e a quantidade, algumas crianças não tinham clareza de como isso funciona. Forçada a se confrontar com situações que põem em xeque seus conceitos, a criança tem a possibilidade de se questionar e desenvolver novas estratégias. 
É possível que o ato de contar as abelhas se deva a vontade de acertar seu lance e ganhar o jogo, vendo como seus colegas resolvem o problema, aquele que está em desvantagem se vê forçado a ajustar sua conduta para que também possa avançar. Aqui, fica claro como o ambiente criado pelo jogo estimula as crianças a enfrentar problemas e criar hipóteses.

Também é possível que o estudante não tenha entendido completamente como estabelecer essa relação entre o número e a quantidade, pois em jogadas em que não contaram as abelhas, esses estudantes erraram a quantidade e, por conseguinte, a jogada.

Outra variável, percebida na aplicação do jogo, foi que, comumente, os jogadores erraram jogadas quando era pedido que relacionassem a quantidade de abelhas com os números sete, oito e nove. Esses erros denotam que é mais difícil estabelecer a relação quando as quantidades são maiores.

Outro fato relevante, nessa pesquisa, foi à constatação realizada pelo professor de que o jogo um diagnóstico capaz de avaliar se os alunos estabelecem relações entre quantidades e números ou se existiam dificuldades que precisariam se mediadas. Essa é uma função do jogo que não foi prevista e, com um olhar atento durante a aplicação, se mostrou viável. Mostrando que situações não convencionais podem fornecer elementos para uma melhor visualização dos conhecimentos dos alunos, fornecendo informações que, de outra maneira, poderiam passar despercebidas, na dinâmica da sala de aula.

Um fato interessante, que constatamos, foi a receptividade da equipe docente à nossa proposta. Não só o professor da turma em que aplicamos o jogo, mas vários professores de outras turmas pediram para aplicar o jogo intitulado "A Corrida dos Números".

Esse fato nos leva a crer que os professores estão procurando novas maneiras de ensinar e que, na realidade, o que falta são novas propostas de ensino, que incluam vivências lúdicas para a sala de aula. Essa reflexão nos leva a um argumento defendido por Matar (2010) de que os jogos comerciais podem ajudar a ensinar.

Reconhecemos a importância de que os designers de jogos se preocupem com temáticas relevantes. Consideramos que jogos podem ajudar a pensar questões da atualidade, mas os jogos comerciais não são suficientes para ensinar conteúdos do currículo. Para dar conta dessa tarefa, precisamos de jogos criados com intenções pedagógicas.

Sem essa intencionalidade, é impossível dar conta de propostas de ensino. Assim, concordamos com autores como Matar (2010) e McGonigal (2012), de que os jogos são um importante meio de ensino de conceitos e de atitudes e que eles terão um papel cada vez maior na sociedade do século XXI.

Assim, nossa proposta é a de que mais jogos sejam propostos por especialistas em educação e que, com o tempo, os especialistas tenham condição de lançar jogos educativos em âmbito comercial. Consideramos esse um movimento que precisa ser considerado como meta para o futuro. 


\section{Referências}

BRASIL. Parâmetros Curriculares Nacionais. Ministério da Educação. Secretaria de Educação Básica. Brasília. 1998.

BRASIL. Base Nacional Comum Curricular. Ministério da Educação. Secretaria de Educação Básica. Brasília. 2016.

GERONIMO, R. R. Uma Aventura no Antigo Egito. Editora Appris. Curitiba. 2017.

HUIZINGA, J. Homo Ludens. Tradução: João Paulo Monteiro. $5^{\text {a }}$ edição. Editora Perspectiva. São Paulo. 2008.

IDE, S. M. O Jogo e o Fracasso Escolar. In: Jogo, Brinquedo, Brincadeira e a Educação. $12^{\mathrm{a}}$ edição. Editora Cortez. São Paulo. 2009.

MATTAR, J. Games em Educação: Como os Nativos Digitais Aprendem. $3^{\text {a }}$ reimpressão. Editora Pearson Prentice Hall. São Paulo. 2010.

MCGONIGAL, J. A Realidade Em Jogo: Porque os Games nos Tornam Melhores e como Eles Podem Mudar o Mundo. Tradução: Eduardo Rieche. Editora Best Seller. Rio de Janeiro. 2012.

MEIRA, L.; PINHEIRO, M. Inovação na Escola. Disponível em: http://www.inovaeduca.com.br/images/opiniao/arquivos/Inovacao_na_escola.pdf, acesso em 23/08/2017.

SEVERINO, A. J. Metodologia do Trabalho Científico. $23^{\text {a }}$ edição. Editora Cortez. São Paulo. 2007.

\section{Biografia Resumida}

Rafael Rix Geronimo: Mestre em Ensino de Matemática pela Pontifícia Universidade Católica de São Paulo. Doutorando em Educação Matemática pela Pontifícia Universidade Católica de São Paulo.

Lattes: http://lattes.cnpq.br/1660997924904848

Contato:rgrix@hotmail.com

Henry Guimarães Teixeira: Licenciado em Pedagogia pela Universidade Universidade Metropolitana de Santos. Professor do Ensino Fundamental da Rede Municipal de São Paulo.

Lattes: http://lattes.cnpq.br/7827845018013752

Contato: henry.guima@hotmail.com 